\title{
Exploring the Model of Combining Medical Treatment and Endowment with Science and Education in China
}

\author{
Xuming Zhang1*, Yuzhen Duan², Hongyu Chen'1, Pandeng Yao1 \\ ${ }^{1}$ School of Public Affair, University of Science and Technology of China, Hefei, China \\ ${ }^{2}$ School of Economics and Management, Anhui Open University, Hefei, China \\ Email: ^17862886619@163.com, dyzp88@mail.ustc.edu.cn, chenhy49@mail.ustc.edu.cn, dyzp88@mail.ustc.edu.cn
}

How to cite this paper: Zhang, X. M., Duan, Y. Z., Chen, H. Y., \& Yao, P. D. (2021). Exploring the Model of Combining Medical Treatment and Endowment with Science and Education in China. Creative Education, 12, 599-617.

https://doi.org/10.4236/ce.2021.123041

Received: March 1, 2021

Accepted: March 21, 2021

Published: March 24, 2021

Copyright $\odot 2021$ by author(s) and Scientific Research Publishing Inc. This work is licensed under the Creative Commons Attribution International License (CC BY 4.0).

http://creativecommons.org/licenses/by/4.0/

\section{(c) (i) Open Access}

\begin{abstract}
The combination of medical treatment and endowment aims to combine medical resources and elderly care resources to maximize the use of social resources. It is a key rehabilitation project in the reform and innovation of human medical care, and it is a practical and feasible new model of medical reform. The paper integrated and combed the connotation of the combination of medical treatment and endowment, and put forward views and suggestions to improve the current model of combination of medical treatment and endowment in China. The paper combines the future development trend of medical treatment and endowment, creatively adding science and education, and proposes a sharing mechanism of science and technology guidance, resource sharing, channel construction, and cost sharing. The research of the project is conducive to enriching the theoretical and practical results of the combination of medical treatment and endowment, and is of great significance to the construction of a harmonious society.
\end{abstract}

\section{Keywords}

Combination of Medical Treatment and Endowment with Science and Education, Social Resource Utilization, Sharing Mechanism

\section{Introduction}

The report of the 19th National Congress of the CPC proposed to "actively respond to the aging of the population, build a policy system for supporting the elderly, filial piety, respect for the elderly and social environment to promote the combination of medical care to speed up the development of undertakings and 
industries for the aged", which pointed out the direction for the practice and exploration of the combination of medical care in China. Massive Health is an overall concept proposed in accordance with the development of the times, social needs and changes in the spectrum of diseases. It revolves around people's basic necessities of life, as well as sickness and death, and focuses on various risk factors and misunderstandings that affect health. It pursues not only individual physical health, but also complete mental, psychological, physical, social, environmental, and moral health. Its scope involves all kinds of health-related information, products and services, as well as the actions taken by various organizations to meet the health needs of the society. As the problems of aging population and empty nesting in our society become more and more serious, how to solve the problems of elderly care and medical care for the elderly in a large health environment has become a key issue of national and social concern. In this context, the report of The 19th National Congress of the CPC clearly pointed out that promote combination of medical treatment and endowment, and accelerate the development of the cause and industry for the elderly. The government has issued corresponding policies to support it. According to data released by the National Bureau of Statistics, as of the end of 2017, there were 241 million people aged 60 and over in my country, accounting for $17.3 \%$ of the total population. Of the 240 million people, nearly 45 million were disabled or semi-disabled. According to predictions by relevant departments, the elderly population will reach 400 million by 2035, and the number of disabled and semi-disabled elderly will further increase. China will have the world's largest population of elderly people. Therefore, faced with the increasing aging population, the weakening of the existing family care function and the elderly's increasingly prominent needs for care, nursing, medical care and other issues, the establishment of a socialized pension service system has become urgent.

In a healthy environment, the combination of medical treatment and endowment has important theoretical and practical value to promote the solution of the medical and elderly care problems caused by the aging of our country's population. Due to the immature development of the theory and practice related to the combination of medical treatment and endowment, this project also provides a foundation and space to enrich and supplement the theoretical and practical research in this field.

\section{Analysis of the Present Situation of the Combination of Medical Treatment and Endowment}

\subsection{The Present Situation of the Combination of Medical Treatment and Endowment}

"Combination of medical treatment and endowment" is the integration of professional medical technology inspections and advanced equipment with rehabilitation training, daily learning, daily diet, and living for the elderly. With medical care as the guarantee and rehabilitation as the support, the policy emphasizes 
the combination of medical treatment and comprehensive treatment. Technically, the patient's functions are maintained or restored as much as possible. Among them, "medical" mainly refers to the early identification of serious diseases, necessary examination, treatment and rehabilitation training, including medical technical services such as prognosis of disease, evaluation and observation, relevant examination, functional rehabilitation, diagnosis and treatment nursing, early intervention of serious diseases and hospice care. In addition to basic medical insurance, the more important thing is to manage the health and chronic diseases of the elderly. "Nursing" cannot be satisfied with the extensive old-age care expansion of "one bed, three meals" in the past (Hart-Malloy, Brown, Bogucki, \& Tesoriero, 2018). Institutional nursing, especially for disabled and semi-disabled elderly, is the core of nursing care, disability care, that is, nursing for the dysfunction caused by aging. "Nurturing" includes services such as physical and psychological nursing, medication and safety, daily diet care, functional training, daily learning, daily activities, critical vital signs, physical condition analysis, and regular weight and nutrition monitoring. Using the development model of "integration of medicine, nourishment and science", the early identification and intervention of serious diseases, early rehabilitation training of serious diseases, daily life, conservation and recuperation, daily learning, nursing and so on are integrated into one department.

At present, the research results of the combination of medical treatment and endowment at home and abroad mainly focus on the qualitative research of the connotation and mode. In terms of discussing the connotation, the combination of medical treatment and endowment is the enrichment and improvement of elderly care services, which is to re-examine the relationship between the contents of elderly care services, and put the health and medical services of the elderly in a more important position (Hazavehei, Khoshravesh, \& Taheri-Kharameh, 2019). It includes traditional life nursing services, mental and psychological services, cultural services for the elderly, and more importantly, medical rehabilitation and health care services, including specific medical services, health consultation services, health examination services, disease diagnosis and treatment and nursing services, rehabilitation services for serious diseases and hospice care services. Some scholars believe that the combination of medical treatment and endowment is to emphasize the two aspects of medical care and life care in the care of the elderly, including medical care, disease diagnosis and treatment, health examination, rehabilitation care, hospice care and other medical and health services for the elderly, as well as daily living, cultural entertainment, psychological care and other life services. Xue, An, Wang, Wu, \& Zhang (2019) believe that the combination of medical treatment and endowment is a new type of elderly care model that combines disease treatment, disease-free recuperation, medical care and elderly care. Its advantage lies in the integration of pension and medical resources, the elderly health and medical services in a more important position, usually by professional nursing staff to take care of the elderly's healthy life and 
daily life, to provide continuous life care and hospice care services.

\subsection{Policy Analysis of the Medical Treatment and Endowment in China}

On June 16, 2014, the National Development and Reform Commission issued the "Notice on Organizing and Launching the Pilot Work of Telemedicine Policy for Elderly Care Institutions", approving Beijing, Hubei Province, and Yunnan Province to launch the "Exploration of Cooperation Mechanisms between Elderly Care Institutions and Medical Institutions" to promote the development of the combination of medical treatment and endowment. By 2015, 14 provinces, cities, and autonomous regions including Beijing, Shanghai, Tianjin, Chongqing, Shandong, Hubei, Hunan, Henan, Fujian, Hainan, Zhejiang, Yunnan, Jiangsu, and Ningxia have successively launched pilot work of the combination of medical treatment and endowment model (Hazavehei et al., 2019). On June 16, 2016, the General Office of the National Health and Family Planning Commission and the General Office of the Ministry of Civil Affairs jointly issued the "Notice on Determining the First Batch of Pilot Units for the Integration of Medical Care at the National Level". 50 cities in 25 provinces, cities, and autonomous regions nationwide (District) as the first batch of national pilot units for the combination of medical treatment and endowment in my country, it is required to start at least one provincial pilot in each province before the end of 2016. On September 14, 2016, the General Office of the National Health and Family Planning Commission and the General Office of the Ministry of Civil Affairs jointly issued the "Notice on Determining the Second Batch of Pilot Units for the Integration of Medical Care at the National Level", identifying 40 cities (districts) including Chaoyang District, Beijing as the second batch of pilot units for the integration of medical care at the national level. This shows that the country is paying more and more attention to the development of the combination of medical treatment and endowment (Xu, Wang, Yuan, Guo, \& Ieee, 2019). On November 2, 2017, the General Office of the National Health and Family Planning Commission issued the "Notice on Printing and Distributing the Key Tasks of the 'Thirteenth Five-Year' Plan for Healthy Aging”, clarifying that the demonstration project for the combination of medical treatment and endowment is led by the National Health and Family Planning Commission, the Ministry of Civil Affairs, cooperate with the National Development and Reform Commission.

\subsection{Analysis on the Practice Model of the Combination of Medical Treatment and Endowment in Foreign Countries}

Taking into account the geographical location of foreign countries, the project team selected typical models of combination of medical treatment and endowment in developed countries from different continents as the research objects, focusing on the model analysis of the United States, Australia, and Germany.

1) United States 
Since the United States entered an aging society in the 1940s, its pension adopts a highly market-oriented commercial insurance care system. However, with the intensification of aging, it is difficult to maintain professional medical care institutions in the United States (Xue, An, Wang, Wu, \& Zhang, 2019). At the same time, due to people yearn to live in the community, the United States has begun a community-based pension model. The main old-age care models are Program of All Inclusive Care for the Elderly (PACE) and Home and Community-Based Services for the Elderly (HCBS). The PACE model is an innovative project that the U.S. government provides comprehensive medical care for the elderly, especially the long-term care for the frail and sickly elderly. It is the most practical in the U.S. long-term care system and is suitable for the elderly with more severe disability and major diseases. The HCBS model is a long-term care system for the elderly that allows the elderly to enjoy convenient life and medical care services in the community or at home, and it also has a significant effect on the recovery of the physical functions of the disabled and semi-disabled elderly. It is suitable for younger people with less disability.

\section{2) Australia}

Australia's geriatric health care system has undergone two changes: the first to divert patients who have been in hospital for a long time to care homes; The second time was in 1980, the government implemented the "family and community care" plan throughout the country, and began to emphasize the importance of family and community care. The old-age care model was transformed from institutional old-age care to community old-age care, and community care has also become the preferred old-age care method for the elderly in Australia. The main old-age care models are residential and home-based care services. Residential service targets are those who have been assessed to be unable to live at home and live in nursing homes, elderly apartments or rehabilitation centers. Home-based services include the provision of home-based and community-based services, as well as extended care and nursing care for related services. In 1997, the passage of the "Elderly Health Care Act" not only provided legal protection for the health of the elderly, but also clarified the government's responsibilities.

\section{3) Germany}

The aging problem in Germany aroused the attention of the government and society in 1990. The German Parliament established the Ministry of Social Welfare, which established and managed six major social welfare organizations in Germany. So far, every social welfare organization has its own apartment for the elderly, nursing homes for the elderly, and training schools for the elderly, making it the first country in the world to establish a public elderly care system. The main old-age care models include home-based care, institutional care, expert care homes and elderly care homes. Home care includes home care, day care and guardianship apartments. Institutional care refers to nursing homes that provide general medical care, nursing and care. Expert care homes provide services for disabled and semi-disabled seniors by professionals. Elderly care homes are 65 Provide services for the one-year-old elderly who need rehabilitation treatment. 


\section{Research on the Sharing Mechanism of Combining Practice of "Medical Treatment and Endowment with Science and Education"}

The entry point of this paper, "medical treatment and endowment with science and education", refers to the integration of science and education content on the basis of the combination of medical treatment and endowment. "Science and education" emphasizes to give priority to the role of science and technology guidance mechanism, that is, through science and technology guidance, science and education to strengthen health, to provide inexhaustible development power for medical treatment and endowment service reform. Among them, the key points of science and technology guidance mechanism include science and technology research and development guidance, science and education personnel guidance, and science and education personnel mainly include in-service/study science and technology personnel and medical personnel, as well as high-quality personnel among retired people. Nursing fields include clinical nursing, preventive health care, nursing management, nursing teaching and nursing scientific research, etc. Students' teaching and practice are normally arranged in the rehabilitation center for the elderly in hospitals, so that the medical treatment and endowment center has the functions of rehabilitation medical treatment, old-age service and teaching practice, and realizes the effective allocation and reasonable integration of social resources. At the same time, we should give full play to the human resources of high-quality retired people in medical treatment and endowment centers (Yu, Lin, Yang, Chen, \& Wang, 2016). At the same time, the relevant units should actively give full play to the human resources of the high quality retired people in the medical treatment and endowment centers, and set up such research centers for the elderly care of retired people, engineering design centers for retired people, and volunteer and mutual aid teams for retired people. It makes the elderly people integrate the rights and responsibilities of serving and being served, and realizes the benign development of medical care and education through system innovation.

\subsection{Science and Technology Guidance Mechanism}

Driven by the demand upgrading of the massive health development and scientific and technological innovation, the combination of medical treatment and endowment needs to constantly transform and upgrade the traditional medical treatment and endowment care services, and create more convenient and high-quality experience for each link. In the combination of "medical treatment and endowment with science and education", "science and education" needs to give full play to the role of science and technology guidance mechanism, and provide inexhaustible development power for the reform of medical care services through science and technology guidance and strengthening health through science and education (Fergus, Kelley, \& Griggs, 2019). At the same time, the combination of scientific research and teaching, and the combination of student training 
and old-age service, on the one hand, provide new learning opportunities for the elderly in medical care centers, and improve the quality of life of the elderly. It makes them gain more respect. On the other hand, the medical treatment and endowment center also provides a practice teaching base for teachers and students majoring in nursing, combining various teaching methods such as simulating the experience of the elderly to realize the normalization of the combination of teaching and accompanying students (Bell \& McCurry, 2020). Under the mode of medical treatment and endowment with science and education, the medical treatment and endowment center has the functions of rehabilitation medical treatment, old-age service, scientific and technological research and development and teaching practice. Teaching practice needs the support of nursing professionals in colleges and universities. The innovative mode of medical science and education is highly compatible with the innovation and entrepreneurship education in the nursing industry, which not only meets the strong needs of the society for nursing staff, but also helps to meet the needs of personal development.

\subsection{Resource Sharing Mechanism}

Facing the incentive market competition, a single entity cannot effectively deal with the combination of medical treatment and endowment by its own strength, and only by breaking through the internal organization can a competitive advantage be established. At the same time, the self-owned resources of the subject cannot be shared due to trust and difference in learning ability, resulting in repeated investment waste, low economic and social benefits and other problems. Therefore, it is of great theoretical and practical significance to study the resource sharing among government, universities, hospitals and social organizations. The shared resources can be divided into tangible resources and intangible resources. Tangible resources refer to those resources that can be seen and touched, such as medical personnel, hardware equipment, rules and regulations, etc., while intangible resources refer to information technology and the reputation of experts that cannot be expressed in a fixed form. The research on resource sharing mechanism is conducive to improving the enthusiasm of resource sharing among the participants in the combination of "medical treatment and endowment with science and education" in practice. Therefore, it helps to improve the efficiency of resource utilization.

\subsection{Channel Construction Mechanism}

"Medical treatment and scientific education" is a long-term process, and all kinds of resources can be more widely recognized and shared only through communication. Therefore, co-construction of channels is conducive to breaking through communication barriers and realizing the sharing of medical and nursing resources. With the continuous development of Internet and big data, the existing medical pension resources have been effectively integrated, which has 
solved the traditional medical pension problems of difficult registration and expensive medical treatment to a certain extent. At the same time, the government has issued policies to encourage hospitals to form medical associations, establish a sharing and exchange system for doctors, carry out graded diagnosis and treatment, promote rational allocation of medical resources, and enhance primary medical capacity. It can be seen that the establishment of diversified resource sharing channels will also become an important force to achieve the goal of combining medical care with nursing care. On the basis of identifying stakeholders, we can actively build various communication platforms, such as encouraging the establishment of regional medical and nursing associations and guiding relevant personnel of medical institutions and pension institutions to strengthen communication. Develop stakeholder relations.

\subsection{Cost-Sharing Mechanism}

In the process of sharing resources, the subject may pay the cost of sharing resources, such as resource transfer cost and risk transfer cost, while getting the shared value. In particular, each subject has the idea of protecting its own resources. Only when the benefits of resource sharing are greater than the costs can sharing be effective and possible. Under normal circumstances, there are four kinds of costs incurred by the government, universities, hospitals and social organizations in the process of resource sharing and channel co-construction, including shared supply cost, shared acquisition cost, shared service cost and shared management cost. The cost of this sharing is not only reflected in money, but also in time and energy. The establishment of a cost-sharing mechanism will provide effective guidance and guarantee for carrying out sharing activities and improving sharing efficiency (Lafferty, 2004). We should give full play to the advantages of information construction and establish a communication and coordination mechanism. Increase capital investment, at the same time, strengthen the training of medical staff and improve the level of treatment. Promote the mode of combining medical treatment and endowment, enhance the effectiveness of policies in ensuring the mode of medical treatment and endowment with science and education, and bring nursing expenses into the reimbursement scope of institutions combining medical treatment and endowment.

\section{Medical Treatment and Endowment with Science Education Model Design}

The society is a complex system, and the symbiosis of the various subsystems in the system is an objective existence. Therefore, in order to deeply understand the health community of medical, nursing, science and education, we must start from its sub-processes, that is, on the basis of accurately grasping the first stage (parasitic vertical) and the second stage (partial benefit symbiosis), specializing in physical, medical and nursing The theoretical construction of a healthy community (mutually beneficial symbiosis). There are three stages in the symbiotic 
relationship structure and evolution process of the medical, nursing, science, education, and health community: the first stage, the teaching, medical, and elderly care departments do not interfere with each other, and each independently manages the execution system, and there is a health supply dilemma with departmental barriers; the second stage, There are corresponding attempts to combine education, medical care, and elderly care institutions, and there is a trend of mutual construction and integration; in the third stage, education, medical care, and elderly care departments gradually break down barriers in departments, management, information, and business (Jin, Xia, Zhang, \& Li, 2018). Work together to meet the needs of the people for health. In the research process of systematic theoretical construction and evolution, the dynamic evolution cannot be separated, nor can the dynamic development from integration to symbiosis be separated. Based on this, the author, based on the theory of social symbiosis, conceives a community of physical, medical and health care as a symbiotic system in which all the main elements of the system have a symbiotic relationship. The community of physical, medical, and health is composed of many symbiotic elements, conforms to the characteristics of the symbiosis system, has the conditions for social symbiosis, and follows the principles and mechanisms of social symbiosis, so as to build a reasonable and scientific social symbiosis relationship and promote the government's physical, medical, and health under the general health needs. Community supply model.

The symbiosis development of the medical, health, science and education community is guided by the social symbiosis theory. To explore its compatibility with the symbiosis theory, it is necessary to start from the soundness of the most basic symbiosis elements. If the medical, nursing, science, education, and health community are regarded as a symbiotic system, the health needs and health supply organizations are the main elements of the symbiotic system of the medical, nursing, science, education, and health community; the public and private resources on which health service activities are carried out are the resource elements of the symbiotic system. The national laws, regulations, and policy provisions of my country's medical care, elderly care services, civil affairs, health science and education, etc., have formed the normative elements of the symbiosis systems. If the basic elements of the symbiosis of the medical, health, science and education community are available, it means that the symbiotic relationship between the subjects in the development of the medical, health, science and education community is long-term and stable, indicating that the symbiotic development of the medical, health, science and education community is a reasonable form of social existence. It constitutes the basic theoretical hypothesis and supporting basis for the symbiosis path design of the medical, nursing, science and education community.

\subsection{Smart Supervision Command Center}

The Smart Supervision Command Center refers to the regional technology com- 
prehensive service platform for the elderly in the big data sector, which is customized and professional for government enterprises. Purchasing government services through third-party technology companies, building a socialized elderly care service platform hub, and supervising and guiding the daily operations of all elderly care institutions, home elderly care service centers, and elderly social organizations within its jurisdiction (Dekhtyar et al., 2020). The purpose is to realize third-party business distribution and smart pension supervision, to realize statistical analysis of data, to provide large-screen data visualization solutions, to guide the elderly service institutions, and to empower and increase efficiency for the elderly. The Smart Supervision Command Center is designed into four parts, including the local elderly care data monitoring system, the elderly home care service center, the elderly health file center and the elderly emergency rescue center.

\section{1) Local pension data monitoring system}

Local pension data monitoring system includes a total ecological science and technology endowment and pension integration platform monitoring command center. It can help create a complete ecological layout of terminal + system + application + content, realize the visual display of local scientific and technological elderly care ecological data, and realize centralized management of local elderly care industry data. It is convenient for local governments, civil affairs bureaus and other competent departments to realize data concentration of local elderly care industry, real-time supervision of the service quality of local elderly care service agencies, emergency command for the elderly, information management area to support the elderly, and future elderly care services in the region.

\section{2) Home Care Center for the Elderly}

The home care center for the elderly mainly cooperates with the smart elderly care supervision system in the form of offline. The third-party business includes offline home service data collection, assisting the development of the home-based elderly service industry, simplifying the initiation of home-based elderly service needs, and improving the quality of local home-based elderly care services. Through the construction of offline home care service centers for the elderly, the supervision and evaluation of the service capabilities of the local government, the Civil Affairs Bureau and other competent departments will be improved, and the authenticity evaluation of the subsidy for the elderly services will be improved.

\section{3) Elderly health record center}

The establishment of a health record center for the elderly can realize the data-based archive management of chronic illness records of the elderly, and provide a complete data link and data precipitation for the local elderly health big data. The smart elderly care supervision system monitors changes in the physical indicators of the elderly in the area, early warning of exceeding the standard, and risk prevention and control, and provides data and technical support for the integration of local medical care. The Elderly Health Records Center can also help connect doctors to realize remote health guidance. 


\section{4) Emergency relief centers for the elderly}

The construction of the emergency rescue center for the elderly includes the $\mathrm{AD}$ special care monitoring system for the elderly and the SOS alarm emergency system for the elderly at home. Through the trinity of PC-side alarm positioning, mobile-side alarm positioning, and mobile-side fence alarm positioning, the elderly in the jurisdiction can receive timely and comprehensive rescue in an emergency. The functions of the emergency rescue center include timely response to the emergency of the elderly in the jurisdiction; multi-end monitoring to prevent the elderly from losing; preventing the elderly at home from not responding to emergency assistance; and providing system support for the command center to make emergency measures in time.

\subsection{Smart Elderly Guardian System}

The Smart Elderly Guardian System is a smart system that integrates multiple practical functions such as smart ward rounds, physical sign data query, abnormal state monitoring and early warning, and health assessment reports under the background of big data. It can be used for in-bed medical care/health care institutions. Physical sign health monitoring and health data management, as well as daily sleep life care for ordinary users' families. The system has the following three characteristics:

\section{1) 24-hour non-inductive monitoring}

On the one hand, different from wearable devices, non-wearable sleep monitoring is adopted, which is safe and non-perceptive, and does not change any sleeping environment and habits, which can minimize the interference to the elderly, especially at night. On the other hand, 24 hours real-time detection of heart rate, breathing rate, resting, physical activity, continuous physical activity, getting out of bed, disconnected, etc., can grasp the vital signs of the elderly at any time, and protect the life of the elderly.

\section{2) Accurate abnormal alarm}

During the monitoring period, if the heart rate exceeds the limit, the respiration rate exceeds the limit, the time to get out of bed, the continuous body movement time exceeds the limit, etc., it can be alerted immediately, the corresponding management personnel can be accurately dispatched, and the alarms can be handled timely and accurately. Night is a high-risk period for elderly care institutions. The system can effectively monitor the elderly who experience tachycardia, bradycardia and other heart rate abnormalities during sleep. By monitoring the early warning information of abnormal signs in real time, it can help deal with dangerous situations in the first time, seize the most precious rescue opportunity to effectively avoid accidents.

\section{3) Analysis of health assessment report}

Through the integration of big data, the key indicators of the elderly can be grasped and the most accurate sleep analysis report can be automatically output. Guardians and senior care facility staff can view the sleep conditions of the elderly in real time, and the organization can perform sleep analysis and sleep 
quality assessment accordingly. It also provides suggestions for the elderly to improve their sleep health. In addition, the organization accurately monitors human vital signs and behavioral habits based on statistical reports and previous sleep reports of the elderly, and analyzes health and disease conditions in combination with big data management to provide more targeted services for the elderly.

\subsection{Online Medical Diagnosis System}

The online medical diagnosis system relies on Internet technology, uses WeChat, APP, small programs, etc. as the carrier, and supports targeted hardware equipment to connect doctors and patients. On the basis of my country's promotion of online medical insurance, the online medical diagnosis system can integrate the medical resources and medical care service resources of local or local institutions, and quickly build a regional online diagnosis and treatment system that connects hospitals, institutions and homes for local people. It can also realize the sinking of medical resource services, broaden the service groups, increase the service radius, improve service quality, and expand the output range of the organization's own medical care service capabilities, so as to increase the income of the organization. In addition, the online medical diagnosis system can quickly build an institution's own online diagnosis and treatment system that does not rely on third-party platforms. The multi-video consultation system provides complete consultation management auxiliary tools to help doctors break through the limitations of time and space and make changes. Efficient and vivid consultation. The online medical diagnosis system products are divided into 5 ends: institutional management end, doctor service end, institution user end, public user end, and institution dispensing end.

\section{1) Institutional management}

As the port of central supervision, the institution management terminal mainly collects the information of doctors in the management institution, arranges personnel scheduling and on-duty, supervises the statistics of doctors' services, records management of all consultations, and checks and controls institution data. Safely guarantee the safety of user resources, doctor resources and even financial data of medical institutions.

\section{2) Doctor service}

The doctor service side mainly includes setting and managing the basic information of doctors, adjusting the online status of doctors, inquiry of doctor scheduling, remote diagnosis and treatment by receiving users, patients' electronic medical records (health records), inquiry of consultation records, issuing electronic prescriptions, and statistical analysis of work data. It is mainly committed to cooperating with the development and implementation of doctors' diagnosis.

\section{3) Institutional user}

Using convenient service portals such as WeChat, APP and small program, the client terminal of the institution is an all-in-one medical and nursing cloud 
diagnosis machine for initiating telemedicine services. It has the characteristics of multi-scene, visualization, simplicity and ease of use, so as to truly realize the combination of Internet and medical and nursing in practice.

\section{4) Public user}

The public user is mainly composed of patients and their families, which is mainly capable of inquiring the information of medical institutions and doctors, initiating remote diagnosis and treatment, inquiring the records of consultation and electronic prescription, and managing family members.

\section{5) Institutional dispensing}

The dispensing terminal of the institution is mainly equipped with electronic prescription scanning code recognition, electronic prescription minimalist flow and dispensing monitoring, user dispensing record management and other functions, which makes diagnosis, prescription and treatment process more integrated and convenient.

\section{Research on the Model of Combining Medical Treatment and Endowment with Science and Education in China}

Under the background of Healthy China, new health industries, new business formats, and new models have emerged and expanded, and the big health industry has entered a golden period of rapid development. Among the many sub-fields of the general health industry, the development speed of the medical care industry is higher than that of other traditional fields such as medical and pharmaceuticals. The big health industry drives medical care for the elderly. The "Opinions" put forward to clearly coordinate the existing resources, and it is expected to set up a number of medical and nursing combination training bases to explore the common universities, vocational colleges, scientific research institutions, industry associations and medical and nursing combination institutions collaborative training mode.

\subsection{The Opportunity of "Internet +" and Build a Resource Integration Platform}

In March 2015, Premier Li Keqiang proposed the "Internet +" action plan at the Third Session of the Twelfth National People's Congress, proposing to integrate the Internet with all walks of life to create a new ecology. The "Guiding Opinions on Actively Promoting the 'Internet +' Action" and the "Guiding Opinions on Promoting the Construction of a Hierarchical Diagnosis and Treatment System" point out that support the full use of the Internet, big data and other information technology means in hierarchical diagnosis and treatment, and clearly and actively explore the extension of the Internet Online medical and health service applications such as medical advice and electronic prescriptions. In May 2018, the General Office of the State Council also issued the "Opinions on Promoting the Development of 'Internet + Medical Health"' researched and drafted by the National Health Commission and other ministries, proposing to improve the "Internet + medical health" service system and improve the "Inter- 
net + medical health" service system. A series of policy measures to promote the in-depth integration of the Internet and medical health, such as the "health" support system. It can be seen that building a platform for integrating medical and nursing resources is an inevitable choice under the "Internet +" opportunity.

\subsection{Develop Smart Elderly Care Equipment and Expand Smart Elderly Care Services}

In February 2017, the Ministry of Industry and Information Technology, the Ministry of Civil Affairs, and the National Health and Family Planning Commission issued the "Smart Health Care Industry Development Action Plan (2017-2020)", which pointed out the use of Internet of Things, cloud computing, big data, and smart hardware. A generation of information technology products can realize the effective docking and optimal allocation of resources for individuals, families, communities, institutions and healthy elderly care, promote the intelligent upgrading of health elderly services, and improve the quality and efficiency of health elderly services (Dimech, Anderson, Lockrow, Spreng, \& Turner, 2019). Promoting the research and development of key technology products and promoting smart health and elderly care services are the key tasks to basically form a smart health and elderly care industry system that covers the entire life cycle. Specifically, it includes breakthroughs in core key technologies, enriching the supply of smart health and elderly care service products, and developing data management and services for health and elderly care. System, foster new business models of smart health and elderly care services, and promote business model innovation for smart health and elderly care. On July 16, 2020, the Ministry of Industry and Information Technology, the Ministry of Civil Affairs, and the National Health and Health Commission issued the "Notice on Launching the Fourth Batch of Pilot Demonstrations for Smart Healthy Elderly Care Applications", which will once again provide additional assistance to the sustainable development of smart elderly care in my country.

\subsection{Broaden Investment and Financing Channels and Develop Financial Services Suitable for the Elderly}

Encourage the pilot construction of the elderly care service industry in a market-oriented way, and improve the marketization level of elderly care services. On October 26, 2019, the National Medical Insurance Administration, the State Administration of Traditional Chinese Medicine, and the 12 departments of the National Office on Aging jointly issued the "Several Opinions on Further Promoting the Development of Integrated Medical Care". The opinions pointed out that the investment and financing channels should be expanded and the society should be encouraged to establish integrated medical care institutions (Sommers, Maylone, Blendon, Orav, \& Epstein, 2017). Of old-age care institutions use equity financing, project financing, etc. to raise start-up funds and development funds. Encourage financial institutions to innovate financial products and finan- 
cial services based on the characteristics of the combination of medical and elderly care, expand diversified investment and financing channels, play a synergistic role of "investment, loan, debt, rent, and certificate", and increase financial support for the integrated medical and elderly care sector. Encourage local governments to explore and improve mortgage loan policies and expand the scope of credit collateral.

In terms of raising funds for the construction of medical care projects, hospitals should actively develop pension trust business with financial institutions, and provide the elderly with more cost-effective and more secure home care, elderly care, emergency rescue and financial management through the innovative model of industry-finance integration. A full range of caring services can also provide rental management services for the elderly's real estate, helping them to maintain and increase the value of their properties. On the basis of the construction of new medicine, expand cooperation with domestic and foreign cooperative units, well-known medical professors, etc. by means of technology shares, carry out medical care crowdfunding projects, and promote the "Internet + crowdfunding + pension" model. In terms of financial services for the medical and nursing population, it is necessary to build a "one-stop" integrated medical and nursing service network platform by integrating the original medical insurance information network and the relevant information of the social security card, and implement the "one-stop" real-time settlement of medical and nursing expenses (Wang et al., 2020). Solve the problem of settlement of medical treatment for the elderly in old-age care institutions with integrated medical treatment and endowment. Hospitals should actively cooperate with commercial banks, insurance companies and other financial institutions to develop wealth management and insurance products suitable for the elderly, and at the same time provide some free health checks for those who have purchased insurance or potential purchasers, actively guide people to treat diseases positively, and encourage patients Realize health management and disease prevention by purchasing commercial health insurance, and realize the integration of maintenance through long-term care insurance.

\subsection{Establish a Resource Sharing Platform and Establish a Green Channel for Medical Care}

"Resource integration" is the sharing and collaboration of funds, human resources, equipment, technology and other management elements between pension institutions and medical institutions. It is an important link in the construction of a pension model combining medical care and nursing. It involves the need to break down the barriers of national health, civil affairs, social security, public security and other departments to achieve resource sharing and collaboration. On October 28, 2019, The National Health Commission, the National Development and Reform Commission, the Ministry of Education and other eight departments jointly issued the Guiding Opinions on the Establishment and Improvement of the Health Service System for the Elderly, emphasizing the coor- 
dination of resources from all government departments and all aspects of society, the mobilization and guidance of the whole society to participate extensively, jointly promote the development of health services for the elderly, and realize joint construction and sharing. Based on the reform of the governance system under the thinking of platform, "platform" refers to an open business ecosystem built by multiple subjects on the basis of equality, sharing resources and achieving win-win results. It can promote the reform of the governance system when it is specifically applied to the old-age care model of "combination of medical treatment and endowment" (Niya, 2020). A database of service institutions of "combination of medical care and nursing care" should be established to gather information. It aims to share information about the physical conditions of the elderly and the medical resources of various institutions on the platform, so as to change the phenomenon of "information island" and "information fragmentation". Under the overall management, the government should make use of the Internet thinking for reconstruction, give full play to its ability to integrate "fragmented" resources, make them form joint forces, create a win-win "combination of medical care" elderly care service ecosystem, and make the resources rationally allocated.

\subsection{Advantages in Science and Education Have Helped Optimize and Upgrade Medical and Nursing Services}

The Guideline on Establishing and Improving the Health Service System for the Elderly was issued on October 28, 2019, emphasizing the need to strengthen discipline development. The government will promote the construction of innovation bases, such as the Geriatric Research Center and the National Clinical Medical Research Center for Geriatric Diseases, to build high-level bases for technological innovation and application of achievements. Elderly health related scientific research should be put on the agenda, and the research and development of prevention, diagnosis and treatment technologies and products related to elderly health should be supported through financial science and technology plans at all levels. Relevant departments should strengthen research and development and promotion of appropriate technologies related to geriatric health, and guide ordinary colleges and vocational schools to offer geriatric medicine, pharmacy, nursing, rehabilitation, psychology, hospice care and other related majors and courses. In the practice of "combination of medical treatment and endowment" for the aged, nursing work and service work can find creativity and solve technical problems through the collective wisdom of people. The cooperation between universities and hospitals and pension institutions can make full use of the manpower, creativity and ability of the volunteer army. At the same time, the service in the "combination of medical treatment and endowment" pension institutions can be taken as one of the contents of social practice and voluntary service for college students. When necessary, credits can be used to encourage and reward them. It can not only improve the practical ability and 
sense of responsibility of college students, but also effectively solve the problem of insufficient nursing staff.

\section{Discussion}

The development of the "medical care, science and education" industry is an important foundation for improving people's health and happiness in life, and is a long-term solution to the new changes in China's social structure and the challenges of an aging population. The Chinese people's unremitting pursuit of life length, abundance and freedom has given "medical science and education" more spiritual and cultural connotations, giving the medical science and education industry more connotation integration and industrial extension possibilities. Although there was no clear concept of "medical and nursing science and education" before, there are already some advanced health centers that practice the model of medical and nursing science and education. Through field surveys and interviews, this article selects advanced cases of "medical care, science and education" for analysis and comparison.

Due to the differences in political system and social and economic development level at home and abroad, the practice of the mode of combining medical treatment and endowment is different. However, due to the late start of the domestic model of combining medical care and nursing care, a mature and unified model has not been established. Combining domestic and foreign medical raise pattern contrast analysis as you can see, each has advantages and disadvantages between different model, so the project on the basis of comparative study, the comprehensive development of our country the truth and the future needs, to cure to raise further perfection and improvement. Suggestions are presented with the model, from the science and education, medical raising modes into and study on a combined mode of practice has a certain guiding significance and innovative.

From the national level, this study puts forward specific countermeasures and suggestions for the operation of the sharing mechanism in the combination of "medical care, science and education". "Medical science and education" in combination with practice, and the main body (such as governments, colleges and universities, hospitals, institutions, social forces, etc.) play a different role, through the study of the sharing mechanism, from science and technology guide, resource sharing, innovative channels to build four aspects, cost sharing, combine of our country to carry out the "medical science and education" of the sharing mechanism, put forward feasible countermeasures and suggestions, will be conducive to the science and education, medical raising mode in the development and implementation of the nationwide.

This study puts forward the implementation path for the combination development of "medical care, science and education" in China at the present stage. With the great attention of the country and the strong appeal of the society, the combination of medical care has set off a boom in the development of the country. The major hospitals have made plans in geriatric medicine, and the devel- 
opment of the combination of medical care is also in its scope of development. The research puts forward a concrete, feasible and innovative implementation path for the combination of "medical, nourishment, science and education", which is of great significance to the specific development of the combination of "medical, nourishment, science and education" in the country (Nematollahi, Esmaelzadeh, Mehdipour-Rabori, \& Bagherian, 2020). Research suggests that the hospital according to "science and education have combined with" implementation path, the preparation to cure the combined with the features of geriatric rehabilitation center, will be built in geriatric rehabilitation center set elderly maintenance center, group medical center, slow aging disease rehabilitation center, gerontology research center, health management center, college of nursing, senile apartment, administrative logistics center eight functions such as plate is a comprehensive medical center. Make its contents include medical treatment, rehabilitation and maintenance, medical, office, living, teaching, scientific research and so on eight areas, achieved based on the provincial capital, services, the province, radiation surrounding, affect the national goal, build the government trust, social reputation, the old piece of health center, improve the elderly health and maintenance facilities conditions, improve the level of aging treatment and research, to achieve good social benefits.

The new mode of collaborative training between universities, vocational colleges, research institutions, industry associations and medical and nursing institutions is conducive to the implementation of the "Healthy China" strategy, the improvement of local people's livelihood and social development, and the realization of a win-win situation for universities and local governments.

The consensus reached by the co-founders and their joint efforts will surely open up new prospects for medical personnel training, medical science and technology, and medical and health care in China.

\section{Acknowledgement}

This work was supported by the "New Medicine" Joint Fund Cultivation Project of University of Science and Technology of China, "Medical Care, Science and Education" Combination Mode and Implementation Path under Big Health Environment, Project No. WK2160000008. All errors are ours.

\section{Conflicts of Interest}

The authors declare no conflicts of interest regarding the publication of this paper.

\section{References}

Bell, C. A. F., \& McCurry, M. (2020). Opioid Use Disorder Education for Acute Care Nurses: An Integrative Review. Journal of Clinical Nursing, 29, 3122-3135.

https://doi.org/10.1111/jocn.15372

Dekhtyar, M., Colford, C., Whisenant, E., Huber, J., Johnson, E., Thomas, P., Wilkerson, L. et al. (2020). Development of Learning Objectives to Guide Enhancement of Chronic Disease Prevention and Management Curricula in Undergraduate Medical Education. 
Teaching and Learning in Medicine, 32, 241-249.

https://doi.org/10.1080/10401334.2020.1724791

Dimech, C. J., Anderson, J. A. E., Lockrow, A. W., Spreng, R. N., \& Turner, G. R. (2019). Sex Differences in the Relationship between Cardiorespiratory Fitness and Brain Function in Older Adulthood. Journal of Applied Physiology, 126, 1032-1041.

https://doi.org/10.1152/japplphysiol.01046.2018

Fergus, T. A., Kelley, L. P., \& Griggs, J. O. (2019). The Combination of Health Anxiety and Somatic Symptoms: A Prospective Predictor of Healthcare Usage in Primary Care. Journal of Behavioral Medicine, 42, 217-223. https://doi.org/10.1007/s10865-018-9956-1

Hart-Malloy, R., Brown, S., Bogucki, K., \& Tesoriero, J. (2018). Implementing Data-to-Care Initiatives for HIV in New York State: Assessing the Value of Community Health Centers Identifying Persons out of Care for Health Department Follow-Up. Aids Care-Psychological and Socio-Medical Aspects of Aids/Hiv, 30, 391-397. https://doi.org/10.1080/09540121.2017.1363851

Hazavehei, S. M. M., Khoshravesh, S., \& Taheri-Kharameh, Z. (2019). Increasing Medical Adherence in Elderly with Type 2 Diabetes Mellitus: A Systematic Review. International Quarterly of Community Health Education, 39, 109-117. https://doi.org/10.1177/0272684X18819969

Jin, X., Xia, Q., Zhang, W., \& Li, L. (2018). Medical-and-Care Wisdom Linkage Pension Model Research and Exploration. Engineering Science, 20, 92-98.

https://doi.org/10.15302/J-SSCAE-2018.02.014

Lafferty, W. E. (2004). Healing, Medical Care, and Health Service Organizations. Journal of Alternative and Complementary Medicine, 10, S141-S146. https://doi.org/10.1089/1075553042245845

Nematollahi, M., Esmaelzadeh, F., Mehdipour-Rabori, R., \& Bagherian, B. (2020). Educational Challenges of Postgraduate Neonatal Intensive Care Nursing Students: A Qualitative Study. Journal of Education and Health Promotion, 9, 171.

https://doi.org/10.4103/jehp.jehp $773 \quad 19$

Niya, L. (2020). Impact of Cloud Computing Data Model on Ldquo the Combination of Medical Care and Pension Rdquo.

Sommers, B. D., Maylone, B., Blendon, R. J., Orav, E. J., \& Epstein, A. M. (2017). ThreeYear Impacts of the Affordable Care Act: Improved Medical Care and Health among Low-Income Adults. Health Affairs, 36, 1119-1128.

https://doi.org/10.1377/hlthaff.2017.0293

Wang, J., Wang, Y., Cai, H., Zhang, J., Pan, B., Bao, G., \& Guo, T. (2020). Analysis of the Status Quo of the Elderly's Demands of Medical and Elderly Care Combination in the Underdeveloped Regions of Western China and Its Influencing Factors: A Case Study of Lanzhou. BMC Geriatrics, 20, 338. https://doi.org/10.1186/s12877-020-01616-6

Xu, J., Wang, M., Yuan, C., Guo, Y., \& Ieee (2019). The Present Situation Analysis and Development Countermeasure of the New Mode of the Combination of Wisdom Pension and Medical Care. 2019 International Conference on Robots \& Intelligent System, Haikou, 15-16 June 2019, 335-338. https://doi.org/10.1109/ICRIS.2019.00091

Xue, L., An, X., Wang, Z., Wu, J., \& Zhang, X. (2019). Feasibility Study on the Combination of Elderly-Care and Medical Care Offered by Community Health Centers. Chinese Journal of Hospital Administration, 35, 529-532.

Yu, W., Lin, D., Yang, B., Chen, X., \& Wang, L. (2016). The Exploration of the Dual Referral Pathway of Treatment-Care Combination for Elderly Patients Based on the Medical Alliance. Chinese Nursing Management, 16, 1452-1455. 